\title{
COMPLEX Y-LINKED TRANSLOCATIONS IN DELIA ANTIQUA PRODUCED BY IRRADIATION OF A FERTILE Y-LINKED TRANSLOCATION
}

\author{
ALAN S. ROBINSON and KEES VAN HEEMERT \\ Foundation ITAL, 6700 AA Wageningen, The Netherlands \\ Received 24.vi.80
}

\begin{abstract}
SUMMARY
In the onion fly, Delia antiqua. a fertile, $\mathrm{Y}$-linked translocation involving chromosomes $\mathrm{Y}$ and 2 was irradiated with fast neutrons to induce new complexes involving the $\mathrm{Y}$-chromosome. This chromosome is male determining in the onion fly. Such complexes can be used for the development of genetic sexing systems and also for the introduction of sterility into field populations following release.

Irradiation reduced egg fertility by 54 per cent and significantly reduced larval survival but it had no effect on the $F_{1}$ sex ratio. By measuring the fertility of $807 \mathrm{~F}_{1}$ males following outcrossing, 112 semi-sterile progenies were isolated of which 11 were lost, 29 showed no inheritance of the semi-sterility, 59 were new autosomal translocations and 13 were new complex $Y$-linked translocations. This classification was accomplished by checking the fertilities of outcrossed $F_{2}$ males and females. Following cytological observation it was revealed that one of these new complexes involved four chromosome pairs, the remainder involved three. There appeared to be no correlation between the fertility of the translocation and the complexity of the rearrangement. The utilization of these rearrangements in the development of the genetic sexing technique for the onion fly is discussed, together with an assessment of their use for fertility reduction in natural populations.
\end{abstract}

\section{INTRODUCTION}

MALE (Y)-linked translocations can be used in insect control in two ways, firstly to introduce sterility into populations (Wagoner et al., 1969; Rabbani and Kitzmiller, 1975a; Baker et al., 1978) and secondly to enable genetic sexing techniques to be developed (Seawright et al., 1978; Baker et al., 1978; Whitten et al., 1976; Curtis et al., 1976; Curtis, 1978). Y-linked translocations with their associated semi-sterility are amongst the simplest types of rearrangement which can be used in genetic control as the translocation is passed to all the sons and none of the daughters, therefore they can be easily maintained in stock. Theoretical studies (Curtis, 1975; Seawright et al., 1979) indicate the usefulness of this type of rearrangement and laboratory (Laven, 1969; Rabani and Kitzmiller, 1975b) and field (Laven et al., 1972) studies have supported this promise.

In the onion fly, Delia antiqua, Y-linked translocations are being isolated both for population sterility induction and genetic sexing. One basic difficulty faced is that the $\mathrm{Y}$-chromosome comprises only 4 per cent of the mitotic chromosome length and as translocations are generally recovered in a frequency relative to their length (Muller and Altenberg, 1930) Y-linked translocations will be disappointingly rare. Out of 71 translocations isolated 
only one was Y-linked (T 61). When first isolated the fertility of translocation males was reduced by 30 per cent but in subsequent generations it regained normal fertility (Van Heemert and Vosselman, 1979). The effective length of the male determining chromosome was therefore increased to 21 per cent of the total chromosome length; this fact together with the full fertility of the translocation made irradiation of this line an attractive proposition for inducing complex Y-linked translocations.

For genetic sexing in the onion fly, dieldrin resistance $(D D)$ and susceptibility (dd) are being used (Towgood and Brown, 1962). T 61 males were backcrossed to the resistant line $D D$ and made homozygous for the resistant allele and irradiated with fast neutrons. In the $F_{1}$ progeny new complex $\mathrm{Y}$-linked translocations were isolated and their fertility and cytology were studied.

\section{MATERIALS AND METHODS}

\section{(i) General procedures}

Adults, larvae and pupae were reared at $23^{\circ} \mathrm{C}$ and $70-80$ per cent R.H. Adults were fed on dried food and larvae reared on onion slices. Egg sterility is used as an initial screen for translocations and eggs were incubated at $29^{\circ} \mathrm{C}$ and 90 per cent R.H. for two days. In the onion fly duplication/deficiency gametes from translocations lead to death in a late embryonic stage causing brown eggs. The presence of such eggs provides a very good marker for the identification of translocations as it is possible to distinguish between fertility reduction caused by translocations and that caused by other factors for example, non-fertilization of the egg. Sterility of translocations is defined as the percentage of brown eggs in the total of brown and hatched eggs.

\section{(ii) Induction and isolation procedure}

Adult males T 61 (Y-2) DD were irradiated with 200 rads fast neutrons (fig. 1) and mated to dieldrin susceptible virgin females (15 cages each with 15 males and 15 females). Two other cages with unirradiated males were used as controls. The fertility of a sample of eggs from each cage was assessed twice. Larval survival was measured by allowing known numbers of first instar larvae access to ample onion, and counting the number of pupae; these were allowed to emerge and pupal survival and adult sex ratio were measured.

The vast majority of the eggs were placed directly on onion and the $F_{1}$ pupae were reared and stored at $2^{\circ} \mathrm{C}$. Periodically, samples were placed at $23^{\circ} \mathrm{C}$ and $\mathrm{F}_{1}$ males were mass-mated to $d d$ females (fig. 1). (As only $Y$-linked translocations were needed, the $F_{1}$ females were discarded.) Following mating, the females were separated and the sterility assessed. Those females showing in excess of 20 per cent sterility were retained and the $F_{2}$ generation reared. As both autosomal and $Y$-linked translocations will be included in this selected group, $F_{2}$ adults of both sexes were again out-crossed to $d d$ females (fig. 1). Where a new Y-linked translocation had been induced all the $F_{2}$ males showed sterility but none of the females. In the case of a new autosomal translocation, half the $F_{2}$ males and half the $F_{2}$ 


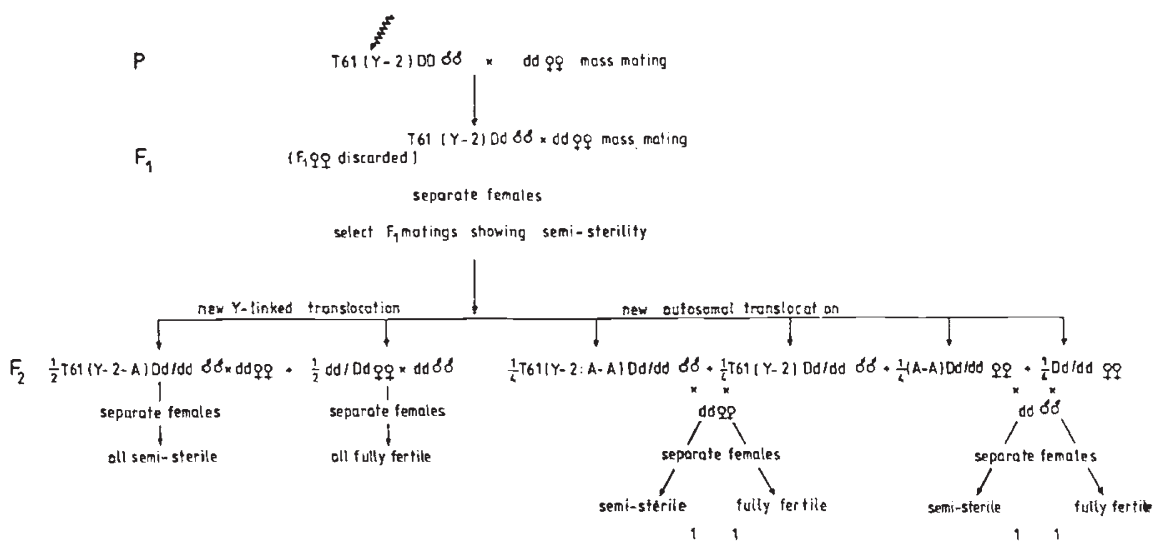

FIG. 1.-Mating scheme for the isolation of complex $Y$-linked translocations $D / d=$ Dieldrin locus; $A=$ an additional autosome.

females showed sterility. The presence of putative Y-linked translocations was confirmed by cytology (for methods see Van Heemert and Vosselman, 1979).

\section{RESULTS}

\section{(i) Radiation-induced dominant lethality}

Table 1 shows the egg fertility of the unirradiated and irradiated Ylinked translocation males. The original Y-linked translocation males exhibit full fertility ( 92 per cent hatch) but following irradiation the fertility was reduced to 38 per cent. Irradiation of normal males with the same dose lead to a fertility in the treated males of 34 per cent (Robinson, 1976). The sterile eggs could be classified into the two types (see Materials and Methods) and both showed a significant increase in frequency following irradiation.

\section{TABLE 1}

Effect of radiation on the fertility of male Delia antiqua carrying a fertile $Y$-linked translocation $(\mathrm{n}=$ number of cages)

\begin{tabular}{|c|c|c|c|}
\hline & \multicolumn{3}{|c|}{ Classification of Eggs } \\
\hline Treatment & $\begin{array}{c}\text { Percentage } \\
\text { unhatched } \\
\text { white } \pm \text { S.E. }\end{array}$ & $\begin{array}{c}\text { Percentage } \\
\text { unhatched } \\
\text { brown } \pm \text { S.E. }\end{array}$ & $\begin{array}{c}\text { Fertile } \\
\text { Percentage } \\
\text { hatched } \\
\pm \text { S.E. }\end{array}$ \\
\hline $\begin{array}{c}0 \operatorname{rad}(n=2) \\
200 \mathrm{rad} \text { F.N. }(n=15)\end{array}$ & $\begin{array}{r}5 \cdot 60 \pm 3 \cdot 40 \\
50 \cdot 20 \pm 1 \cdot 22\end{array}$ & $\begin{array}{r}2 \cdot 35 \pm 1 \cdot 65 \\
11 \cdot 33 \pm 0 \cdot 82\end{array}$ & $\begin{array}{l}92 \cdot 05 \pm 5 \cdot 05 \\
38 \cdot 47 \pm 1 \cdot 09\end{array}$ \\
\hline
\end{tabular}

Radiation-induced lesions leading to early egg lethality and white eggs are probably caused by early inhibition of mitosis due to the formation of chromosome bridges (Smith and Von Borstel, 1972) and in Drosophila (Von Borstel and Rekemeyer, 1959) they constitute the major portion of radiation induced dominant lethality. However, late embryonic lethals (brown 
eggs) are probably caused by chromosome imbalance as this type of lethality can be mimicked by aneuploid gametes from different types of chromosomal rearrangements (Robinson, 1977).

The vast majority of radiation induced dominant lethals are egg lethals but nevertheless a small proportion can be expressed in later stages (table 2 ).

TABLE 2

Effect of radiation on larval and pupal survival following radiation of male Delia antiqua carrying a fertile $\mathrm{Y}$-linked translocation

\begin{tabular}{|c|c|c|c|}
\hline & $\begin{array}{c}\text { Larval } \\
\text { survival } \\
(\% \pm \text { S.E. })\end{array}$ & $\begin{array}{c}\text { Pupal } \\
\text { survival } \\
(\% \pm \text { S.E. })\end{array}$ & $\begin{array}{cc}\text { Percentage } & \text { Percentage } \\
\text { females } & \text { males } \\
\pm \text { S.E. } & \pm \text { S.E. }\end{array}$ \\
\hline $\begin{array}{l}0 \mathrm{rad} \\
X_{\text {HET }}^{2} \text { d.f. }=9\end{array}$ & $\begin{array}{c}73 \cdot 60 \pm 4 \cdot 06 \\
45 \cdot 29 * * *\end{array}$ & $\begin{array}{c}90 \cdot 05 \pm 3 \cdot 41 \\
25 \cdot 96^{* *}\end{array}$ & $\begin{array}{c}50 \cdot 95 \pm 3 \cdot 1049 \cdot 05 \pm 3 \cdot 10 \\
8 \cdot 95 \text { n.s. }\end{array}$ \\
\hline $\begin{array}{l}200 \mathrm{rad} \text { F.N. } \\
X_{\text {HET }}^{2} \text { d.f. }=9\end{array}$ & $\begin{array}{c}62 \cdot 81 \pm 5 \cdot 80 \\
72 \cdot 16^{* * *}\end{array}$ & $\begin{array}{c}89.32 \pm 1.60 \\
7.41 \text { n.s. }\end{array}$ & $\begin{array}{c}54 \cdot 16 \pm 4 \cdot 3145 \cdot 84 \pm 4 \cdot 31 \\
17 \cdot 38^{*}\end{array}$ \\
\hline $\begin{array}{l}X^{2}(0 \mathrm{rad} \text { v.s. } 200 \mathrm{rad}) \\
\text { d.f. }=1\end{array}$ & $13 \cdot 44^{* * *}$ & 1.64 n.s. & $\begin{array}{r}X_{1}^{2}(\text { sex ratio } 1: 1)=0.42 \\
\text { n.s. }\end{array}$ \\
\hline $\begin{array}{l}* P<0.05 \quad * * P \\
\text { n.s. }=\text { not significant }\end{array}$ & $* * * F$ & & \\
\hline
\end{tabular}

They significantly reduce larval survival in the irradiated series when the overall totals were compared. However, in both series there was significant heterogeneity between replicates. This often occurs during larval rearing of the onion fly where onion quality plays an important role in larval survival. Pupal survival and adult sex ratio were unaffected by the radiation (table 2).

\section{(ii) Sterility of the $F_{1}$ generation}

Over a period of a year samples of $F_{1}$ pupae were removed from the $2^{\circ} \mathrm{C}$ storage and emerged. The $\mathrm{F}_{1}$ males $(D d)$ were mass-mated with $d d$ females and the sterilities of these females is illustrated in fig. 2 ; it is very similar to that recorded when normal males were irradiated with 200 rads of fast neutrons (Robinson and Van Heemert, 1980a). Out of 807 separated females 695 (86 per cent) showed no clear increase in sterility and were discarded. The remaining 112 females exhibited sterilities ranging from 20 per cent to over 80 per cent, however there did appear to be a peak around the 45-50 per cent level. Eleven females in the right hand section of the distribution did not leave sufficient progeny in order to produce an $F_{2}$ generation leaving 101 semi-sterile progenies.

\section{(iii) Classification of the $F_{2}$ progenies}

$\mathrm{F}_{2}$ progenies, both male and females were mass-mated to $d d$ flies (fig. 1). Subsequently the mated females were separated and their fertility assessed. Using this information conclusions could be drawn concerning the genetic constitution of the $F_{1}$ male.

(a) If both male and female $F_{2}$ showed normal fertility then a factor or factors other than an inheritable rearrangement caused the reduction in 


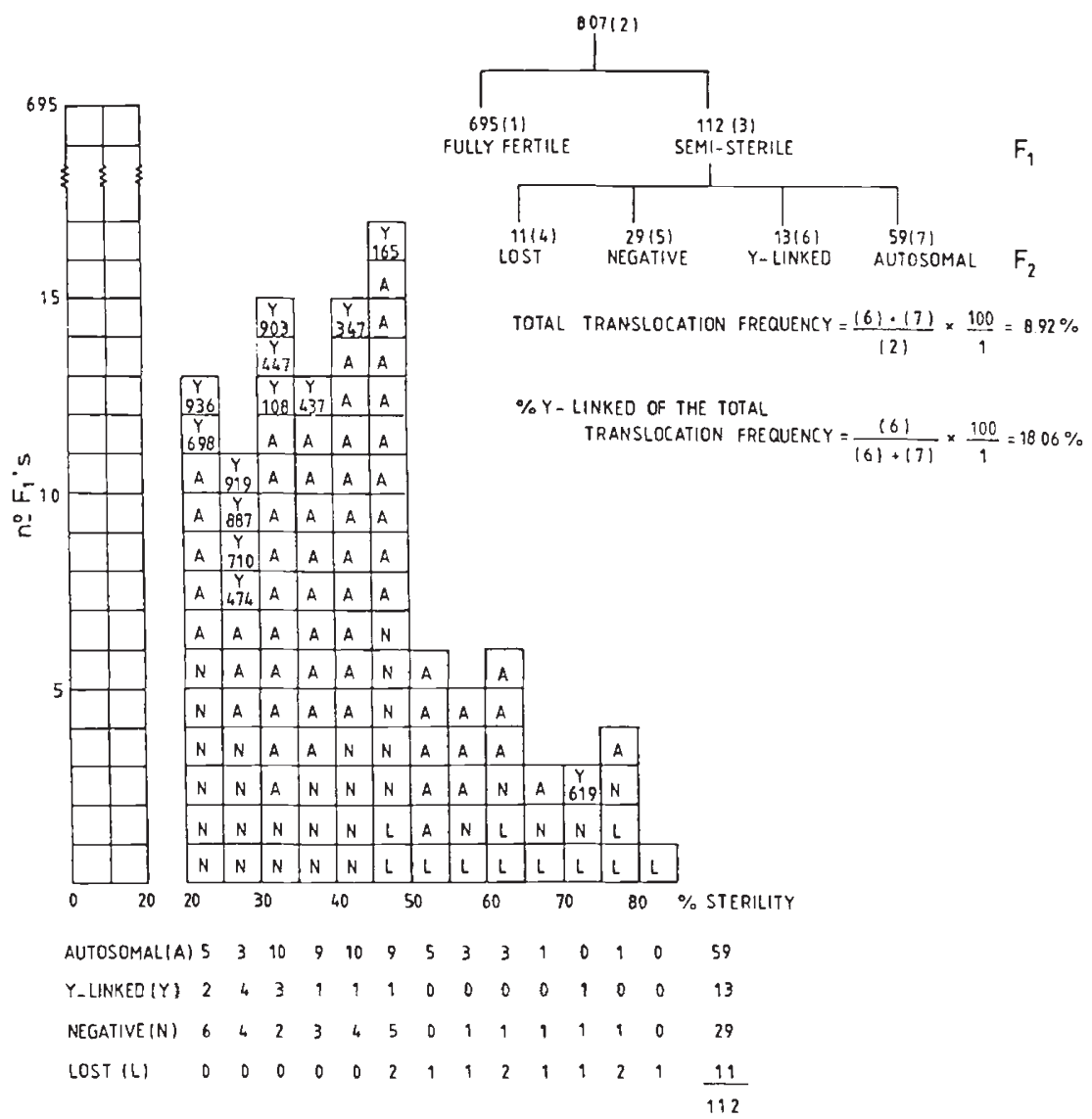

FIG. 2.-Fertility distribution of $F_{1}$ males descended from irradiated $T 61$ males and the classification of the $F_{2}$ progenies.

fertility in the $F_{1}$ male. In fig. 2 these cases are represented by $\mathrm{N}$ and as expected more were found at slightly reduced fertility levels.

(b) If half the $\mathrm{F}_{2}$ males and half the females show a decreased fertility this gives a strong indication that an autosomal translocation was present in the $F_{1}$ male. In fig. 2 these cases are represented by $A$ and 59 were observed. They were found at all fertility levels.

(c) If all the $F_{2}$ males showed a reduced fertility but all the $F_{2}$ females had normal fertility then the presence of a Y-linked translocation was suggested. In fig. 2 these are represented by $Y$ together with the $F_{1}$ number; a total of 13 was isolated.

The overall frequency of translocation induction was 8.92 per cent which agrees well with equivalent data when normal males are irradiated (Robinson and Van Heemert, 1980a). However, what is different is the proportion of the translocation which was $\mathrm{Y}$-linked, 18 per cent, a frequency which agrees very well with the expectation based on chromosome length (21 per cent) of the Y-2 translocation complex. 


\section{(iv) Fertility and cytology of the complex Y-linked translocations}

In all cases $\mathrm{Y}$-linked translocations were confirmed by cytological analysis and it became clear that in two cases a single $F_{1}$ male had mated with two females. Translocations T 447 and T 473 were identical and translocations T 903 and T 919 were also identical (table 3). However, this did

TABLE 3

Cytology and sterility of complex Y-linked translocations in Delia antiqua

\begin{tabular}{|c|c|c|c|}
\hline $\begin{array}{c}\text { Translocation } \\
\text { Number }\end{array}$ & $\begin{array}{l}\text { Chromosomes } \\
\text { Involved }\end{array}$ & $\begin{array}{c}\text { Percentage } \\
\text { Sterility } \pm \text { S.E. }\end{array}$ & $\begin{array}{l}\text { No. males } \\
\text { tested } \\
\text { for sterility }\end{array}$ \\
\hline Т 108 & $Y-2-5^{1}$ & - & - \\
\hline T 165 & $Y-2-6^{1}$ & $30 \cdot 72 \pm 1 \cdot 80$ & 12 \\
\hline Т 347 & $Y-2-5^{1}$ & $38 \cdot 52 \pm 1 \cdot 55$ & 18 \\
\hline T 447$\}$ & $Y-2-3^{1}-6^{1}$ & $50 \cdot 57 \pm 1 \cdot 85$ & 13 \\
\hline T 474 & $Y-2-3^{1}$ & $34 \cdot 32 \pm 2 \cdot 14$ & 14 \\
\hline Т 619 & $Y-2-6^{s}$ & $63 \cdot 15 \pm 4 \cdot 86$ & 10 \\
\hline Т 698 & $Y-2-6$ & $17 \cdot 56 \pm 1 \cdot 51$ & 9 \\
\hline T 710 & $Y-2-6 ?$ & & \\
\hline Т 887 & $Y-2-3^{1}$ & $31 \cdot 90 \pm 1 \cdot 36$ & 6 \\
\hline $\left.\begin{array}{l}\text { T } 903 \\
\text { T } 919\end{array}\right\}$ & $Y-2-3^{1}$ & $35.93 \pm 1.84$ & 19 \\
\hline Т 936 & $Y-2-3^{s}$ & $26 \cdot 27 \pm 1 \cdot 62$ & 13 \\
\hline
\end{tabular}

not invalidate the calculation of the translocation frequency if it is assumed that all $F_{1}$ males have an equal chance of mating twice. In one case, $T 447$ ( $T$ 473) a complex involving four chromosome pairs was identified, the rest all involved three chromosome pairs. Four involved chromosomes $\mathrm{Y}-2-3$, two involved Y-2-5 and three or four involved Y-2-6. Chromosome 4 was conspicuous by its absence from these complexes (table 3 ).

Photomicrographs of two types (a triple and a quadruple) are presented in fig. 3 together with a normal karyotype (fig. 3a) and the original Y-linked translocation $\mathrm{T}(\mathrm{Y}-2)$ (fig. $3 \mathrm{~b}$ ) between chromosome arm $2^{1}$ and $\mathrm{Y}$ (acrocentric). $\mathrm{T} 165$ (figs. $3 \mathrm{c}$ and $\mathrm{e}$ ) has been derived from $\mathrm{T}(\mathrm{Y}-2)$ by a break at about the original breakpoint in the short arm of chromosome 2 , close to the centromere. The other breakpoint was proximal in the long arm of chromosome 6 . Together with three bivalents a hexavelent can be observed in fig. $3 \mathrm{c}$, in which three chromosome pairs are included. This translocation is schematically represented in fig. $3 \mathrm{e}$. T 447 (or T 473) has chromosomes 3 and 6 in the complex and in fig. $3 \mathrm{~d}$ an octavalent is present in meiotic prophase as well as the two bivalents from chromosomes 4 and 5 . Following radiation three breaks occurred and a cyclic triple translocation was produced superimposed on $\mathrm{T}(\mathrm{Y}-2)$. The three breaks occurred in the long arms of the chromosomes 2, 3 and 6. Thus in total five breakpoints occurred to form a complex of eight chromosomes (fig. 3f).

The translocations exhibited a wide range of partial sterility from 17 to 63 per cent when males were testcrossed in subsequent generations. Interestingly the two translocations exhibiting the lowest levels of sterility, T 936 and $T 698$ were isolated from $F_{1}$ males from the lowest sterility class (fig. 2); the same was true for the least fertile translocation T 619 (fig. 2). So far none 


\section{Plate I}
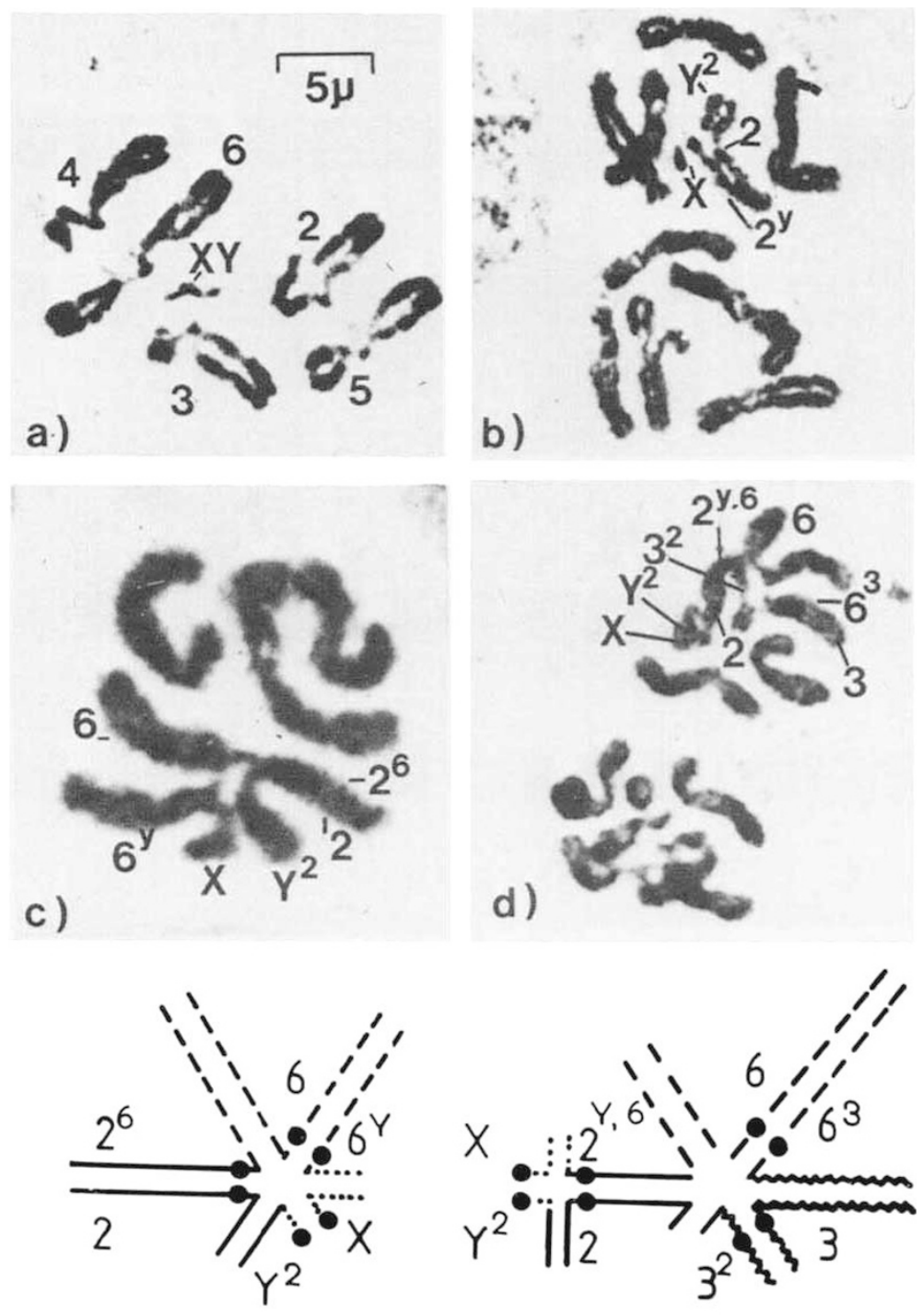

e )

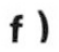

FIG. 3.-Meiotic configurations of male Delia antiqua $(2 n=10+\mathrm{XY})$; a, normal karyotype; b, Y-linked translocation (T 61); c, Y-linked complex translocation T 165; d, Y-linked complex translocation $\mathrm{T} 447$; e and $\mathrm{f}$, schematic representations of $\mathrm{T} 165$ and $\mathrm{T} 447$ respectively. 
of the translocations has recovered fertility as occurred with the original Y-linked translocation and there appears to be no relation between the complexity of the translocation and the sterility.

\section{Discussion}

Following irradiation of a Y-linked translocation (Y-2), eleven new complex $\mathrm{Y}$-linked translocations were isolated, but two were lost. The sterilities showed a wide range of values and there was no obvious clustering round the 50 per cent level. The male linked translocations were isolated firstly to develop a genetic sexing system and secondly for use to exert a genetic load in a natural population. For these two uses different fertility criteria apply. For genetic sexing high fertility is necessary, so that mass rearing can be carried out efficiently but for the introduction of a genetic load a lower degree of fertility is desired, for example that exhibited by T 619.

What was unexpected was the lack of any relationship between the complexity of the translocation and its sterility. This is in contrast to most other species where an increase in complexity of rearrangements is always accompanied by an increase in sterility (Wagoner et al., 1969; McDonald et al., 1978).

In a previous report (Van Heemert and Robinson, 1981) concerning breakpoint distribution in 70 autosomal translocations it was shown that chromosome 4 was seldom recovered in rearrangements; the same appears now to be true for Y-linked complex translocations.

The recent successful development of genetic sexing in Drosophila by using the ADH locus (Robinson and Van Heemert, 1980 b), the localization of the ADH locus in the onion fly on chromosome 6 (Van Heemert and Witteveen-Pillen, 1980) and the presence of a Y-linked translocation with chromosome 6 suggest also this approach for the development of a genetic sexing system in the onion fly.

Acknowledgements. - Dr Harris of the Research Institute, London, Ontario, Canada kindly provided the dieldrin strains. The expert technical assistance of W. van den Brink and G. Schelling is gratefully appreciated.

\section{REFERENCES}

BAKER, R, H., SAKAI, R. K., SAIFUDDIN, U. 'T., AND PERVEEN, A. 1978. Induced chromosomal aberration in Anopheles culicifacies. Mosquito News, 38, 370-376.

CURTIS, C. F. 1975. Male-linked translocations and the control of insect pest populations. Experientia, 31, 1139-1140.

CURTIS, C. F. 1978. Genetic sexing separation in Anopheles arabiensis and the production of sterile hybrids. Bull. W.H.O., 56, 453-456.

CURTIS, C. F., AKIYAMA, J., AND DAVIDSON, G. 1976. A genetic sexing system in Anopheles gambiae species. A. Mos. News., 36, 492-496.

HEEMERT, C. VAN, AND ROBINSON, A. S. 1981. Cytogenetic analysis and breakpoint distribution of radiation induced interchanges in Hylemya antiqua. Submitted to Genetica.

HEEMERT, C. VAN, AND VOSSELMAN, L. 1979. A male linked translocation with high fertility in the onion fly, Hylemya antiqua. Genetica, 51, 111-114.

HEEMERT, C. VAN, AND WITTEVEEN-PILLEN, I. (1980). Location of the alcohol dehydrogenase gene in the onion fly Hylemya antiqua (Meigen) using a translocation in a tester set. J. Hered., 71, 364-365. 
LAVEN, H. 1969. Eradicating mosquitoes using translocations. Nature, 221, 958-959.

LAVEN, H., COUSSERANS, J., AND GUILlE, G. 1972. Eradicating mosquitoes using translocations: A first field experiment. Nature, 236, 456-457.

MCDONALD, P. T., ASMAN, S. M., AND TERWEDOW, H. A. 1978. Sex linked translocations in Culex tarsalis: chromosome-linkage group correlation and segregation patterns, $J$. Hered., 69, 304-310.

MULlER, M. J., AND ALTENBERG, E. 1930. The frequency of translocations produced by X-rays in Drosophila. Genetics, 15, 283-311.

RABBANI, M. G., AND KitZmiller, J. B. 1975a. Studies on X-ray induced chromosomal translocations in A. albimanus. I. Chromosomal translocations and genetic control. Am. J. Trop. Med. Hyg., 24, 1019-1026.

RABbANi, M. G., AND KiTZMIller, J. B. 1975b. Studies on X-ray induced chromosomal translocations in Anopheles albimanus. II. Laboratory evaluation of sexual competitiveness of translocation males. Am. J. Trop. Med. Hyg., 24, 1027-1030.

ROBINSON, A. S. 1976. Production of chromosomal rearrangements by X-rays and fast neutrons in Hylemya antiqua in relation to genetic control. In The Use of Ionizing Radiation in Agriculture, pp. 345-350. C.E.E. Workshop Wageningen.

ROBINSON, A. S. 1977. Genetic control of Hylemy a antiqua. I. X-ray induced effects in the $F_{0}$ and $\mathrm{F}_{1}$ generations. Mut. Res., 42, 79-88.

ROBINSON, A. S., AND HEEMERT, C. VAN. 1980 $a$. Translocations induced by fast neutrons and X-rays in Delia antiqua. Submitted to Theoret. Appl. Genet.

ROBINSON, A. S., AND HEEMERT, C. VAN. $1980 \mathrm{~b}$. Genetic sexing in Drosophila melanogaster using the alcohol dehydrogenase locus and a Y-linked translocation. Theoret. Appl. Genet. In press.

SEAWRight. J. A., HAILE, D. G., RABBANi, M. G., AND WEIDHAAS, D. E. 1979. Computer simulation of the effectiveness of male linked translocation for the control of Anopheles albimanus. Am. J. Trop. Med. Hyg., 28, 155-160.

SEAWRIGHT, J. A., KAISER, P. E., DAME, D. A., AND LOFGREN, C. S. 1978. Genetic method for preferential elimination of females of Anopheles albimanus. Science, 200, 1303-1304.

SMITH, R. H., AND VON BORSTEL, R. C. 1972. Genetic control of insect populations. Science, $178,1164-1174$.

TOWGOOD, J. G., AND BROWN, A. W. A. 1962. Inheritance of dieldrin resistance in the onion maggot. Can. J. Genet. Cytol., 4, 160-171.

VON BORSTEL, R. C., AND REKEMEYER, M. L. 1959. Radiation induced and genetically contrived dominant lethality in Habrobracon and Drosophila. Genetics, 44, 1053-1074.

WAGONER, D. E., NICKEL, C. A., AND JOHNSON, D. A. 1969. Chromosomal translocation heterozygotes in the house fly. J. Hered., 60, 301-304.

WHITTEN, M. J., FOSTER, G. C., VOGT, W. G, KITCHING, R. L., WOODBURN, T. L., AND KONOVALOV, C. 1976. Current status of genetic control of the Australian sheep blowfly, Lucilia cuprina. Prox. XV Intern. Congr. Entomol, pp. 129-239. Washington D.C. 